\title{
Maternal Diabetes: A Potential Risk Factor of Congenital Hearing Loss
}

\author{
Angeli C. Carlos-Hiceta, MD and Maria Rina T. Reyes-Quintos, MD, PhD \\ Department of Otorhinolaryngology, Philippine General Hospital, University of the Philippines Manila
}

\begin{abstract}
Objective. The purpose of this study is to identify the incidence rate of 'refer' result in neonates born to diabetic mothers and to determine the association of maternal diabetes and the initial 'refer' result.

Methods. This was a retrospective cross-sectional study which included neonates who had hearing screening test using transient-evoked otoacoustic emissions test (TEOAE) on both ears at the Philippine General Hospital Ear unit during three weeks. We obtained the demographic characteristics, presence/absence of maternal diabetes, and OAE results.

Results. Among the 150 neonates, ten were born to diabetic mothers, with an age range of 2-8 days old. Forty percent of neonates of diabetic mothers had an initial 'refer' result compared with $7.9 \%$ of nondiabetic mothers' neonates. After logistic regression analysis, there is a significant association between maternal diabetes and initial 'refer' result in OAE with a $p$-value $<0.05$. If the mother is diagnosed with diabetes (gestational/pre-gestational), the odds of having an initial 'refer' result in the hearing screening is $2 x$ higher. The odds can range from 2-43 times.
\end{abstract}

Conclusion. The incidence rate of an initial 'refer' result in neonates of diabetic mothers is $40 \%$. There is a significant association between maternal diabetes and the initial 'refer' result in the OAE test.

Key Words: maternal diabetes, neonates of diabetic mothers, risk factor, hearing loss, newborn hearing screening

\section{INTRODUCTION}

Congenital hearing loss is a significant concern worldwide. On June 12, 2009, Republic Act 9709, or the Universal Newborn Hearing Screening and Intervention Act of 2009, was signed into law, establishing a program for preventing, early diagnosis, and hearing loss intervention. As stated, all infants born in the Philippines should undergo hearing screening shortly after birth, before one month of age.

By recognizing and identifying the risk factors affecting neonatal hearing loss, the Joint Committee on Infant Hearing $(\mathrm{JCIH})$ and the implementation of the universal newborn hearing screening aimed to determine those patients needing intervention. Early detection is vital for immediate intervention and rehabilitation. We are currently following the 1-3-6 schedule, which includes the three key components in the early detection and intervention program, namely screening for the 1 st month, confirmatory test or follow-up screen and diagnostic on the 3rd month, early

Corresponding author: Angeli C. Carlos-Hiceta, MD Department of Otorhinolaryngology Philippine General Hospital University of the Philippines Manila Taft Avenue, Manila 1000, Philippines Email: angeli.hiceta@gmail.com intervention by six months of age.

The Joint Committee on Infant Hearing (JCIH) listed the following risk indicators affecting hearing in newborn: (1) caregiver concern regarding hearing, speech, language, or developmental delay, (2) family history of permanent 
childhood hearing loss, (3) NICU > 5 days, (4) in utero infections, such as CMV, herpes, (5) craniofacial anomalies, (6) physical findings, (7) syndromes, (8) neurodegenerative disorders, (9) culture-positive postnatal infections, (10) head trauma, and (11) chemotherapy. The list was only able to identify $50 \%$ of infants with hearing loss. The presence of diabetes in mothers is not part of the list, but studies have shown possible association.

Diabetes mellitus, a metabolic disorder, and its complications continue to affect and haunt our society in this age. Its prevalence in the United States is increasing as it inflicts $10-14 \%$ of the adult population. ${ }^{1,2}$ In a local study by Soria, Sy, Vega et al. (2009), their cohort showed an incidence rate of $16.3 \%$ of type 2 diabetes mellitus among Filipinos after nine years and a prevalence rate of $28 \%{ }^{3}$ The course of the disease, including its devastating complications, are well documented. However, diabetic pregnancy and its effect on infant's health status, especially on hearing, have yet to be studied and discovered. According to the Center for Disease Control and Prevention, diabetic pregnancy puts both the mother and the infant at risk for adverse health outcomes. ${ }^{1}$ The physiologic derangements of diabetes during pregnancy include modifications in the maternal glucose levels, lipids, and amino acids, leading to the unavailability of these essential substrates to the developing fetus. ${ }^{4-7}$ The hostile environment and adverse conditions created by this illness affects the general health status of the fetus before delivery and contributes to the neonatal outcome. ${ }^{8,9}$ Diabetes is a known teratogenic; a lot of early research showed a significantly higher rate of genetic malformations and fetal complications like congenital heart diseases, in this population. ${ }^{10-14}$ In a study by Malong, Sila-Atanacio, AndagSilva \& Cunanan (2013), of the 173 patients diagnosed with gestational diabetes in a tertiary hospital in the Philippines, $16 \%$ had fetal complications, including meconium aspiration, hypoglycemia, pneumonitis, sepsis, hydropnephrosis, and inguinal hernia; $4 \%$ resulted to neonatal death. ${ }^{15}$

Complications of diabetes in pregnancy, such as congenital craniofacial anomalies, chronic intrauterine hypoxia and ischemia, and abnormal birth weight, just to name a few, are known indicators for neonatal hearing loss. Its potential effect and alteration on developing auditory system should be considered. ${ }^{16}$ There have been no studies in the Philippines regarding the association of maternal diabetes and initial 'refer' result and the direct association between maternal diabetes and congenital hearing loss. Thus, the purpose of this study is to identify the incidence rate of 'refer' result in neonates born to diabetic mothers and to determine the association of maternal diabetes and the initial 'refer' result.

\section{MATERIALS AND METHODS}

This retrospective cross-sectional study included neonates with hearing screening tests using transient- evoked otoacoustic emissions test (TEOAE) on both ears at the Philippine General Hospital Ear unit for three weeks. Inclusion criteria comprise mothers age 18-45 years old with or without diabetes (pregestation or gestational). Exclusion criteria are the following: preterm neonates with cleft palate, microtia, and other congenital anomalies/syndromes or who are born to mothers with gross or documented hearing loss. This study was approved by the University of the Philippines Manila Research Ethics Board (UPMREB 2019-363-01). The board waived informed consent.

Patients were seen at the Philippine General Hospital Ear Unit. The following data were collected: age (days) and sex of neonate, birth weight (grams), age of mother (years), and initial OAE result for both ears. Initial OAE result pertains to the result of the hearing screening test before hospital discharge. Neonates were brought to a quiet room for the $\mathrm{OAE}$ procedure. Testing was done while the baby is quiet or asleep by two trained personnel using Otometrics Madsen AccuScreen SN 806004, SN 304884, and SN 304885. Results, either 'pass' or 'refer,' were printed and relayed to the parents or relatives. A 'pass' result would indicate a response from functional outer hair cells in the cochlea. Simultaneously, a 'refer' outcome is the absence of one or a possible problem in the external or middle ear that may affect the conduction of sound to the inner ear. If the result is 'refer,' the patient is asked to return after one month for re-testing. Deidentified data were tabulated, encoded, and summarized into frequencies and percentages using the MS Excel for Mac v.15.13.3 (2015, Microsoft Corp., Redmond, WA). Odds ratio and multiple logistic regression were performed using Stata Statistical data analysis 14.1 Special Edition software to find any significant association between maternal diabetes and the initial 'refer' result of neonates before discharge. A p-value of less than 0.05 was considered statistically significant.

\section{RESULTS}

A total of 150 neonates were included in this study with an age range of 1-9 days old and a birth weight range of 19003800 grams. Of the 150 neonates, seventy-eight (52\%) were males, seventy-two (48\%) were females. Seventeen percent of the neonates have low birth weight (1500-2500), while most (83\%) have appropriate birth weight.

Among the 150 neonates, 7\% (10) were born to diabetic mothers, with an age range of 2-8 days old. Of these ten neonates, thirty percent were born to a high-risk mother in terms of age ( $\leq 35$ years old). Thirty percent were born within the birth weight of 1500 to 2500 grams, considered as low birth weight; seventy percent have appropriate birth weight. Of this particular group of neonates, $40 \%$ (4) of which had a 'refer' result on TEOAE: 2 have an initial 'refer' result on both ears, while the other 2 have initial 'refer' result on just one ear. Summary profiles and raw data of these patients are seen in Tables 1 and 2, respectively. 
Table 1. Profile of Neonates of Diabetic Mothers

\begin{tabular}{ll}
\hline Age of neonates & 2-8 days old \\
\hline Age of mothers & $21-37$ years old \\
& Low risk $=7(70 \%)$ \\
& High risk=3 $(30 \%)$ \\
\hline Sex & $M=7(70 \%)$ \\
& $\mathrm{F}=3(30 \%)$ \\
\hline Birth weight & $2400-3800$ grams \\
& Low $=3(30 \%)$ \\
& Appropriate $=7(70 \%)$ \\
\hline OAE result & Pass $=6(60 \%)$ \\
& Refer $=4(40 \%)$ \\
\hline
\end{tabular}

Table 2. Raw Data of Neonates of Diabetic Mothers

\begin{tabular}{|c|c|c|c|c|c|c|}
\hline \multirow{2}{*}{$\#$} & \multirow{2}{*}{$\begin{array}{c}\text { Age of } \\
\text { neonate } \\
\text { (days) }\end{array}$} & \multirow{2}{*}{$\begin{array}{c}\text { Sex of } \\
\text { neonate }\end{array}$} & \multirow{2}{*}{$\begin{array}{c}\text { Birth } \\
\text { weight } \\
\text { (grams) }\end{array}$} & \multirow{2}{*}{$\begin{array}{l}\text { Age of } \\
\text { mother } \\
\text { (years) }\end{array}$} & \multicolumn{2}{|c|}{ OAE result } \\
\hline & & & & & Right & Left \\
\hline 1 & 2 & $M$ & 3100 & 31 & Pass & Pass \\
\hline 2 & 2 & $\mathrm{~F}$ & 3000 & 35 & Pass & Pass \\
\hline 3 & 8 & $M$ & 3800 & 28 & Pass & Pass \\
\hline 4 & 4 & $M$ & 2400 & 26 & Pass & Pass \\
\hline 5 & 2 & $\mathrm{~F}$ & 3300 & 29 & Refer & Refer \\
\hline 6 & 2 & $M$ & 2400 & 37 & Pass & Pass \\
\hline 7 & 3 & $M$ & 2800 & 30 & Pass & Pass \\
\hline 8 & 2 & $M$ & 3500 & 21 & Pass & Refer \\
\hline 9 & 4 & $M$ & 2400 & 35 & Refer & Refer \\
\hline 10 & 2 & $\mathrm{~F}$ & 2800 & 22 & Pass & Refer \\
\hline
\end{tabular}

Table 3. Logistic Regression Summary Results

\begin{tabular}{lccc}
\multicolumn{1}{c}{ Variable } & OR crude & 95\% $\mathbf{C l}$ & p-values \\
Diabetes & 7.82 & 1.91 to 31.93 & 0.004 \\
Age of neonate & 0.58 & 0.36 to 0.96 & 0.033 \\
Sex of neonate & 2.32 & 0.68 to 8.00 & 0.179 \\
Birth weight & 1.00 & 1.00 to 1.003 & 0.10 \\
Maternal age & 1.00 & 0.93 to 1.08 & 0.955 \\
Diabetes* & 9.25 & 1.95 to 43.84 & 0.005 \\
\hline
\end{tabular}

${ }^{*}$ Adjusted for age, sex, weight, and maternal age

We found that $40 \%$ of neonates of diabetic mothers have an initial 'refer' result compared with $7.9 \%$ of the neonates of nondiabetic mothers. Among neonates with initial 'refer' result patients, 7\% has low birth weight and was born to a diabetic mother. Among neonates with 'refer' result patients, $7 \%$ was born to a high-risk mother in terms of age ( $>35$ years old) and is diabetic at the same time.

A simple logistic regression analysis on each variable, namely maternal diabetes, age of neonate, sex of neonate, birth weight, maternal age, only diabetes, and neonatal age, has significant p-values, hence correlation with 'refer' result. On multiple logistic regression analysis after controlling for the other variable, the result showed a significant association between maternal diabetes and the initial 'refer' result in OAE $(p<0.05)$. If the mother is diagnosed with diabetes, whether gestational or pre-gestational, the odds of having a 'refer' result in the hearing screening test (TEOAE) is
$2 \mathrm{x}$ higher. The odds can range from 2 to 31 times. Results of multiple logistic regression analysis are in Table 3.

\section{DISCUSSION}

The prevalence of gestational diabetes in the Philippines was reported to be $14 \% .{ }^{15}$ The purpose of this study is to establish maternal diabetes as a risk factor for congenital hearing loss. The study's long-term objectives are to determine if there is a significant association between maternal diabetes and congenital hearing loss and eventually identify whether infants of diabetic mothers are at risk for hearing loss. However, only a few studies have explored the auditory function and communication disorders in this population. ${ }^{17}$ A study by Kountakis (2002) has proposed maternal diabetes as one of the risk factors for hearing loss. Stanton's (2005) findings have shown that maternal diabetes does not significantly increase the neonatal DPOAE screening failure rate. ${ }^{17,18}$ Gratz (1981) presented two case reports where maternal diabetes was the only potential teratogenic factor identified. Both patients presented with ipsilateral facial palsy and hearing loss associated with hypoplasia of the internal auditory canal. ${ }^{19}$ In another study by Ewart-Toland, Yankowitz, Winder et al. (2000), of the twenty-one infants with diabetic mothers, $43 \%$ have hearing loss, including sensorineural, conductive, and mixed hearing loss. ${ }^{20}$ Our study revealed an association between maternal diabetes and a 'refer' result. Forty percent of the neonates of diabetic mothers had an initial 'refer' result in the hearing screening test. Our findings suggest that a history of maternal diabetes significantly increases the neonatal TEOAE screening refer result by $2 \mathrm{x}$. This makes maternal diabetes still a potential risk factor for congenital hearing loss. To establish this study's long-term objective, the confirmatory test should be done to determine an association between maternal diabetes and congenital hearing loss. This would, even more, strengthen our goal of including maternal diabetes as a risk factor. A study by Kountakis showed that of the nine infants of diabetic mothers, 4 (44\%) failed in a follow-up ABR screen. ${ }^{18}$

Having an initial refer result will alarm the parents, and they will be informed early on the possibility of a congenital hearing loss in their baby. They will be appropriately advised on the next steps to take and the important schedule to remember. Another relevant issue is auditory neuropathy, which presented with normal OAEs but absent or abnormal ABR. Infants with diabetic mothers present with hypoxia, ischemia, and hyperbilirubinemia are also found in infants with auditory neuropathy ${ }^{17}$. Potential dysfunction in such a disease may be the inner hair cell, auditory nerve, and the synapse between these cells. ${ }^{17}$ These areas are might be vulnerable to the metabolic derangements brought about by maternal diabetes during fetal development. Thus, proper selection of initial hearing screening tests should be considered. According to Stanton (2005), selective 
inner hair cell damage in infants of diabetic mothers is a possibility. Otoacoustic emissions (OAEs), which we used in our study, measure cochlear activity, precisely the function of the outer hair cells or the 'active' mechanisms in the cochlea. ${ }^{20}$ It only detected pathology related to the outer hair cells. Therefore, our study showed that outer hair cells might also be involved in the pathology of diabetes, possibly due to the metabolic derangements brought about by diabetes.

The association of referring OAE result and maternal diabetes in this study is based on the initial hearing screening only. One of the limitations of this study is the short period of data collection. We are unable to include in this study the re-screening and confirmatory test results. Re-screening is done after one month of the initial test, and confirmatory tests are scheduled after re-screening if necessary. Another limitation of this study is the small sample size. To accurately establish a hearing loss, a re-screening and confirmatory test must be done. This study may serve as a pilot study for future studies in determining if maternal diabetes is predictive of congenital hearing loss after the confirmatory test (ABR). I would recommend a follow-up on this study to include larger sample size and a longer duration for the study to follow-up on 'refer' patients and see the results of rescreening and confirmatory test, if necessary. The confidence interval in this study is too broad. This would indicate a low power or a low sample. Hence a larger sample size is highly recommended. Future studies might also want to differentiate between pre-gestational and gestational diabetes and level of control (controlled vs. uncontrolled based on HBA1c) and determine if there is an association with congenital hearing loss. Based on literature, even when diabetic mothers achieved a clinically acceptable glycemic control level, normal physiology is not restored. Well-controlled diabetic pregnancies still have some modifications in the body's substrates affecting fetal development. ${ }^{17}$

In conclusion, given the significant association between maternal diabetes and 'refer' results, diabetes mellitus can still be considered a potential risk factor for congenital hearing loss. The incidence rate of an initial 'refer' result in neonates of diabetic mothers is $40 \%$. There is a significant association between maternal diabetes and the initial 'refer' result in the OAE test. If the mother has diabetes, a 'refer' result in screening OAE is $2 \mathrm{x}$ more likely. By emphasizing a healthy maternal status and adequate prenatal care, we can secure and promote the unborn child's welfare. We hope to increase the detection rate by being familiar with and discovering other neonatal hearing loss risk factors. Thus we can screen, diagnose, save, and rehabilitate more infants.

\section{Acknowledgments}

We would like to acknowledge Aljo Molina, MD, $\mathrm{PhD}$, for helping with the statistics. We would also like to acknowledge Ms. Mary Jane Yapo and PGH-Ear Unit staff for helping us with this study.

\section{Statement of Authorship}

Both authors participated in data collection and analysis, and approved the final version submitted.

\section{Author Disclosure}

Both authors declare no conflicts of interest.

\section{Funding Source}

This paper was self-funded.

\section{REFERENCES}

1. Centers for Disease Control and Prevention. Proposed recommendations for action: A national public health initiative on diabetes and women's health (CDC Interim Rep.). Atlanta, GA: Author; 2001.

2. The Expert Committee on the Diagnosis and Classification of Diabetes Mellitus. Report of the expert committee on the diagnosis and classification of diabetes mellitus. Diabetes Care. 2000 Jan; 23(1):S4-19.

3. Soria MLB, Sy RG, Vega BS, Ty-Willing T, Abenir-Gallardo A, Velandria $\mathrm{F}$, et al. The incidence of type 2 diabetes mellitus in the Philippines: A 9-year cohort study. Diabetes Res Clin Pract. 2009 Nov; 86(2):130-3. doi: 10.1016/j.diabres.2009.07.014.

4. Susa JB, Gruppuso PA, Widness JA, Domenech M, Clemons GK, Sehgal P, et al. Chronic hyperinsulinemia in the fetal rhesus monkey: Effects of physiologic hyperinsulinemia on fetal substrates, hormones, and hepatic enzymes. Am J Obstet Gynecol. 1984 Oct; 150(4): 415-20. doi: 10.1016/s0002-9378(84)80150-7.

5. Freinkel N. Banting Lecture, 1980: Of pregnancy and progeny. Diabetes. 1980 Dec; 29(12):1023-35. doi: 10.2337/diab.29.12.1023.

6. Kalkhoff RK. Impact of maternal fuels and nutritional state on fetal growth. Diabetes. 1991 Dec; 40 Suppl 2:61-5. doi: 10.2337/ diab.40.2.s61.

7. Silverman BL, Purdy LP, Metzger BE. The intrauterine environment: Implications for the offspring of diabetic mothers. Diabetes Reviews. 1996 Jan; 4(1):21-35.

8. Langer O, Conway DL. Level of glycemia and perinatal outcome in pregestational diabetes. J Matern Fetal Med. 2000 Jan-Feb; 9(1):35-41. doi: 10.1002/(SICI)1520-6661(200001/02)9:1<35::AIDMFM8>3.0.CO;2-6.

9. Weintrob N, Karp M, Hod M. Short- and long-range complications in offspring of diabetic mothers. J Diabetes Complications. 1996 Sep-Oct; 10(5):294-301. doi: 10.1016/1056-8727(95)00080-1.

10. Becerra JE, Khoury MJ, Cordero JF, Erickson JD. Diabetes mellitus during pregnancy and the risks for specific birth defects: A population-based case-control study. Pediatrics. 1990 Jan; 85(1):1-9.

11. Mills JL. Malformations in infants of diabetic mothers. Teratology. 1982 Jun; 25(3):385-94. doi: 10.1002/tera.1420250316.

12. Molsted-Pedersen L, Pedersen JF. Congenital malformations in diabetic pregnancies. Clinical viewpoints. Acta Paediatr Scand Suppl. 1985; 320:79-84. doi: 10.1111/j.1651-2227.1985.tb10143.x.

13. Pedersen LM, Tygstrup I, Pedersen JF. Congenital malformations in newborn infants of diabetic women. Correlation with maternal diabetic vascular complications. Lancet. 1964 May; 1(7343):1124-6. doi: 10.1016/s0140-6736(64)91805-7.

14. Lisowski LA, Verheijen PM, Copel JA, Kleinman CS, Wassink $\mathrm{S}$, Visser GHA, et al. Congenital heart disease in pregnancies complicated by maternal diabetes mellitus: An international clinical collaboration, literature review, and meta-analysis. Herz. 2010 Jan; 35(1):19-26. doi: 10.1007/s00059-010-3244-3.

15. Malong CL, Sila-Atanacio A, Andag-Silva A, Cunanan E. Incidence of postpartum diabetes and glucose intolerance among Filipino patients with gestational diabetes mellitus seen at a tertiary hospital. J ASEAN Fed Endocr Soc. 2013 May; 28(1):56-63. doi: 10.15605/ jafes.028.01.11 
16. Joint Committee on Infant Hearing. Year 2000 position statement: Principles and guidelines for early hearing detection and intervention programs. Am J Audiol. 2000 Jun; 9(1):9-29.

17. Stanton SG, Ryerson E, Moore SL, Sullivan-Mahoney M, Couch SC. Hearing screening outcomes in infants of pregestational diabetic mothers. Am J Audiol. 2005 Jun; 14(1):86-93. doi: 10.1044/10590889(2005/008).

18. Kountakis SE, Skoulas I, Phillips D, Chang CYJ. Risk factors for hearing loss in neonates: A prospective study. Am J Otolaryngol. 2002 May-Jun; 23(3):133-7. doi: 10.1053/ajot.2002.123453.
19. Gratz ES, Pollack MA, Zimmerman RD. Congenital facial palsy and ipsilateral deafness: association with maternal diabetes mellitus. Int J Pediatr Otorhinolaryngol. 1981 Dec; 3(4):335-41. doi: 10.1016/01655876(81)90058-6.

20. Ewart-Toland A, Yankowitz J, Winder A, Imagire R, Cox VA, Aylsworth AS, et al. Oculoauriculovertebral abnormalities in children of diabetic mothers. Am J Med Genet. 2000 Feb; 90(4):303-9.

Have you read the current trends in Medical and Health Research in the Philippines?

\title{
Acta Medica Philippina The National Health Science Journal
}

\author{
Access Online: www.actamedicaphilippina.upm.edu.ph
}

